\title{
Haluaako lehmä laiduntaa?
}

\author{
Leena Tuomisto $^{1)}$, Lilli Frondelius ${ }^{2)}$, Jaakko Mononen ${ }^{2)}$, Auvo Sairanen ${ }^{1)}$ \\ ${ }^{1)}$ Maa- ja elintarviketalouden tutkimuskeskus, Kotieläintuotannon tutkimus, Halolantie 31 A, 71750 \\ Maaninka,etunimi.sukunimi@mtt.fi \\ ${ }^{2)}$ Kuopion yliopisto, Biotieteiden laitos, PL 1627, 70211 Kuopio, frondeli@hytti.uku.fi, jaak- \\ ko.mononen@uef.fi
}

\section{Tiivistelmä}

Maidontuotannon rakennemuutoksesta johtuva tilakokojen suureneminen voi johtaa siihen, että laidunala ei enää riitä ja laiduntamisen järjestäminen suurelle eläinmäärälle on vaikeaa. Koska laiduntamisen kuitenkin katsotaan yleisesti vaikuttavan edullisesti nautojen hyvinvointiin, tutkimuksessa selvitettiin lehmien tarvetta laiduntaa. Kokeen 24 lehmää oli jaettu kahteen 12 lehmän ryhmään, jotka laidunsivat ympäri vuorokauden pois lukien lypsyajat. Kontrolliryhmän eläimet laidunsivat tavanomaisesti, mutta koejaksojen aikana häkkiryhmän lehmille tarjottiin lisäksi samalta laidunlohkolta niitettyä ruohoa ruokintahäkistä. Kaikki lehmät saivat väkirehua lypsyjen yhteydessä ( 9 kg/lehmä/vrk). Koejaksojen, yksi heinäkuussa ja yksi elokuussa, kesto oli viisi vuorokautta. Lehmiä tarkkailtiin hetkellisellä seurannalla kymmenen minuutin havaintovälillä koejaksojen viimeisen $48 \mathrm{~h}$ ajan pois lukien lypsyajat (klo 05:30-09:00 ja 14:30-18:00). Tilastollinen testaus tehtiin lineaarisella sekamallilla käyttäen yksittäisten lehmien havaintoja toisistaan riippumattomina havaintoina. Mallissa kiinteinä tekijöinä olivat käsittely, koejakso sekä näiden yhdysvaikutus ja satunnaistekijänä blokki. Häkkiryhmän lehmät laidunsivat vähemmän kuin kontrolliryhmän eläimet (keskimäärin 3,5 vs. 7,1 h vuorokaudesta, $\mathrm{P}<0,001$ ), ja käyttivät vuorokaudesta keskimäärin 2,6 h häkistä tarjotun rehun syömiseen. Kaikkiaan häkkiryhmän lehmät käyttivät syömiseen vähemmän aikaa kuin kontrolliryhmän eläimet (keskimäärin 6,1 vs. $7,1 \mathrm{~h}$ vuorokaudesta, $\mathrm{P}<0,001)$. Häkkiryhmän eläimet märehtivät enemmän kuin kontrolliryhmän eläimet (keskimäärin 6,9 vs. 6,3 h vuorokaudesta, $\mathrm{P}<0,05$ ). Kontrolli- ja häkkiryhmän lehmien välillä ei ollut eroa lehmien kävelemiseen (keskimäärin 0,2 vs. $0,2 \mathrm{~h}$ vuorokaudesta), muuhun aktiivisuuteen makuulla ja seisaalla ( 1,0 vs. $1,1 \mathrm{~h})$, joutilaana makaamiseen ja seisomiseen $(3,0 \mathrm{vs.} 3,3 \mathrm{~h})$ tai yhteensä makaamiseen (8,6 vs. 9,1 h) käyttämässä ajassa. Kun lehmillä oli mahdollisuus hankkia ravintonsa laiduntamalla tai syömällä ruokintahäkistä, ne valitsivat helpomman häkkiruokintavaihtoehdon vain osittain. Kokeemme tulokset viittaavat siihen, että lehmillä on tarve hankkia ainakin osa ravinnostaan laiduntamalla. Lehmän sosiaalinen asema ja terveys saattavat kuitenkin vaikuttaa yksittäisten lehmien tekemiin valintoihin.

Asiasanat: lehmät, laidun, käyttäytymistarve, käyttäytyminen, laiduntaminen, syömiskäyttäytyminen 


\section{Johdanto}

Laiduntamisen katsotaan yleisesti vaikuttavan edullisesti naudan hyvinvointiin. Se muun muassa mahdollistaa lajityypillisen syömiskäyttäytymisen ja sosiaalisen kanssakäymisen lajitovereiden kanssa. Laiduntaessaan naudalla on myös mahdollisuus valikoida syömänsä kasvit ja niiden osat. Laiduntamisen ja päivittäisen liikunnan on todettu vaikuttavan positiivisesti lehmien terveyteen (Gustafson 1993, Haskell ym. 2006). Laidunrehun käyttö on myös taloudellisesti järkevää (Sairanen ym. 2004). Vaikka laidunnus on ollut perinteenä Euroopassa, on siitä monin paikoin luovuttu tuotannon tehostamisen ja tuotantoteknologian kehittymisen myötä. Joillakin alueilla laiduntaminen ei myöskään ole enää taloudellisin tapa käyttää maata (Haskell ym. 2006). Suomessa pihatossa olevia lehmiä ei välttämättä tarvitse laiduntaa, mutta 1.7.2006 voimaan tulleen asetuksen mukaan parsinavetoissa olevat lypsylehmät ja hiehot on laidunkauden aikana päästettävä vähintään 60 päivänä laiduntamaan tai jaloittelemaan (Valtioneuvoston asetus 171/2005).

Maidontuotannon rakennemuutos on johtanut Euroopan Unionin alueella mukaan lukien Suomessa lypsykarjatilojen vähenemiseen ja tilakokojen suurenemiseen. Joissakin tapauksissa kasvava lehmäluku on johtanut siihen, että laidunala ei enää riitä ja laiduntamisen järjestäminen suurelle eläinmäärälle on vaikeaa (Holma 2008). Muita ongelmia laidunnukselle ja jaloittelulle aiheuttaa se, ettei parsinavetoiden ympäristöä ole aina suunniteltu silmällä pitäen eläinten ulkoilua. Lehmien kulkureitit saattavat olla hankalia ja jopa vaarallisia (mäkinen maasto, vilkasliikenteiset tiet). Myös etäisyys laitumelle saattaa olla liian suuri (Sairanen ym. 2004). Lypsyrobotin käyttö on yleistynyt viime vuosina ja sen käytön yhdistäminen laiduntamiseen on toisinaan hankalaa.

Koska laiduntamisen katsotaan yleisesti vaikuttavan edullisesti lehmien hyvinvointiin, tutkimuksessa selvitettiin lehmien tarvetta laiduntaa. Kokeessa selvitettiin, valitseeko lehmä mieluummin helposti ruokintahäkistä saatavan ravinnon kuin työläämmän laiduntamisen.

\section{Aineisto ja menetelmät}

Koe tehtiin Maa- ja elintarviketalouden tutkimuskeskuksen (MTT) Pohjois-Savon tutkimusasemalla heinä-elokuussa 2007. Kokeessa käytettiin 24 holsteinlehmää. Kokeen ajaksi lehmät lainattiin toisesta, koko laidunkauden (1.6.-30.8.2007) kestävästä kokeesta, jossa tutkittiin laidunkauden lisävalkuaisvastetta lypsylehmillä. Lehmät jaettiin kahteen 12 lehmän koeryhmään. Koeryhmiin jakoa varten lehmät jaettiin blokkeihin tuotoksen ja poikimakerran mukaan (korkeatuottoiset, keskituottoiset, matalatuottoiset ja ensikot).

Kokeessa oli kaksi viiden päivän pituista koejaksoa, ensimmäinen heinäkuussa ja toinen elokuussa. Koejakson kolmen ensimmäisen vuorokauden aikana lehmät saivat totutella koeolosuhteisiin ja kahden viimeisen vuorokauden aikana lehmien käyttäytymistä tarkkailtiin. Lehmät olivat koejakson ajan laitumella pois lukien lypsyajat (klo 05:30-09:00 ja 14:30-18:00). Lypsyn ajaksi lehmät ajettiin navettaan ja kiinnitettiin parsiin. Toinen 12 lehmä ryhmä (kontrolliryhmä) laidunsi koejakson ajan tavanomaisesti. Myös toinen 12 lehmän ryhmä (häkkiryhmä) laidunsi koejakson ajan, mutta lisäksi sille tarjottiin samalta laidunlohkolta niitettyä ruohoa ruokintahäkistä, joka oli sijoitettu laitumelle. Ympyrän muotoisen ruokintahäkin halkaisija oli $200 \mathrm{~cm}$ ja siinä oli $40 \mathrm{~cm}$ levyiset ruokailupaikat 18 eläimelle. Ruokintahäkki sijoitettiin aina laitumen portin puoleiseen päähän. Lehmille tarjottiin laitumella vapaasti vettä vesiautomaateista. Lisäksi kaikki lehmät saivat väkirehua lypsyjen yhteydessä (9 $\mathrm{kg} / \mathrm{lehmä/vrk).}$

Laidunlohkojen koko määräytyi laitumen massan mukaan niin, että tarjolla olevan laitumen määrä oli $25 \mathrm{~kg} \mathrm{ka} / \mathrm{vrk}$ eläintä kohti. Ryhmien laidunlohkot olivat toisistaan noin sadan metrin etäisyydellä ryhmien välisen käyttäytymisen synkronisaation minimoimiseksi. Jokaisen iltalypsyn yhteydessä laidunlohkoa vaihdettiin. Lohkon vaihdon yhteydessä häkkiryhmälle annettiin uusi annos niitettyä ruohoa. Niitetty ruoho punnittiin ennen laitumelle viemistä ja myös jäljelle jäänyt jäte punnittiin lohkon vaihdon jälkeen. Lohkosta (ja tarjotusta rehusta) otettiin rehunäytteet, joista tehtiin Valiolla raaka-aineanalyysi ja määritettiin D-arvo NIR -menetelmällä. Analyysien perusteella ensimmäisen jakson rehu oli nuorta ja hyvälaatuista (D-arvo $737 \mathrm{~g} / \mathrm{kg}$ ), ja toisen jakson rehu oli kelvollista (D-arvo $705 \mathrm{~g} / \mathrm{kg}$ ).

Koejakson kahden viimeisen vuorokauden ajan lehmiä tarkkailtiin hetkellisellä seurannalla kymmenen minuutin havaintoväliä käyttäen (Martin \& Bateson 1993). Tarkkailu kesti kummallakin koejaksolla kaksi vuorokautta pois lukien lypsyajat (klo 05:30-09:00 ja 14:30-18:00). Tarkkailussa kirjattiin ylös kymmenen minuutin välein kunkin eläimen asento ja käyttäytymistoiminto taulukossa 1 
esitetyn luokittelun mukaisesti. Elokuussa yötarkkailussa apuna käytettiin taskulamppuja. Kummankin tarkkailujakson aikana sää oli aurinkoinen tai poutainen, paitsi elokuussa ensimmäisen yön aikana oli raju ukkosmyrsky.

Taulukko 1. Tarkkailussa käytetyt käyttäytymisluokat.

\begin{tabular}{ll}
\hline Käyttäytyminen & Kuvaus \\
\hline Laiduntaa & $\begin{array}{l}\text { Lehmä liikkuu hitaasti turpa maan läheisyydessä ja nyhtää, pureskelee ja nielee } \\
\text { ruohoa. }\end{array}$ \\
Syö rehua ruokintahäkistä & $\begin{array}{l}\text { Lehmä syö niitettyä ruohoa ruokintahäkistä; lehmä ottaa rehua suuhun kielen ja } \\
\text { huulten avulla, pureskelee ja nielee. }\end{array}$ \\
Märehtii & Märepala nousee lehmän suuhun. Lehmä pureskelee ja nielee märepalan. \\
Kävelee & Lehmä kävelee pää ylhäällä määrätietoisesti useita askeleita. \\
On joutilaana & Lehmä on tekemättä mitään. \\
Muu aktiivisuus & Lehmän muut toiminnot kuin yllä esitetyt: esimerkiksi juominen, sosiaalinen \\
& käyttäytyminen, kävelyä nopeampi liikkuminen, kehon hoito, ympäristön \\
tutkiskelu. & Lehmä on navetassa lypsyllä. \\
Lypsyllä & Lehmä seisoo pää ylhäällä. \\
Seisoo & Lehmä makaa rintalastan päällä tai kyljellään. \\
Makaa &
\end{tabular}

Aineistosta poistettiin yksi lehmä poikkeavan käyttäytymisen vuoksi. Tilastollinen testaus tehtiin SPSS for Windows 14.0 -ohjelmalla. Muuttujat analysoitiin lineaarisella sekamallilla. Tilastollisen testauksen mahdollistamiseksi yksittäisten lehmien havaintoja käytettiin mallissa toisistaan riippumattomina havaintoina. Mallin yleinen muoto oli: $Y_{i j k l}=\mu+\beta_{i}+\gamma_{j}+\beta \gamma_{i j}+\theta_{k}+\varepsilon_{i j k l}$, jossa $i=1$, 2 (käsittely), $j=1,2$ (koejakso), $k=1,2,3,4$ (blokki), $l=1,2,3, \ldots, 23$ (eläinyksilö). $Y_{i j k l}=$ käyttäytymistoiminnon osuus havainnoista, $\mu=$ yleiskeskiarvo, $\beta_{i}=$ käsittelyn $i$ kiinteä vaikutus, $\gamma_{j}=$ koejakson $j$ kiinteä vaikutus, $\beta \gamma_{i j}=$ käsittelyn ja koejakson yhdysvaikutus, $\theta_{k}=$ blokin satunnaisvaikutus ja $\varepsilon_{i j k l}=$ virhetermi. Mallissa käytettiin toistomittausten kovarianssirakennetta (Compound symmetry, Heterogeneous compound symmetry), joista sopivampi valittiin Akaiken informaatiokriteerin perusteella.

Laiduntamisen ja häkkirehun syömisen vuorokausirytmien esitystä varten laskettiin kultakin tarkkailutunnilta laiduntavien ja häkkirehua syövien lehmien keskimääräinen lukumäärä. Vuorokausirytmejä ei testattu tilastollisesti, vaan tulokset on esitetty kuvaajina.

\section{Tulokset ja tulosten tarkastelu}

Häkkiryhmän lehmät laidunsivat vähemmän kuin kontrolliryhmän eläimet (keskimäärin 3,5 vs. 7,1 h vuorokaudesta, $\mathrm{P}<0,001$ ), ja käyttivät vuorokaudesta keskimäärin 2,6 h häkistä tarjotun rehun syömiseen (Taulukko 2). Kontrolliryhmä käytti kaikkiaan syömiseen yhtä paljon aikaa molempina tarkkailukertoina, mutta häkkiryhmällä syömiseen käytetty aika lisääntyi elokuussa verrattuna heinäkuuhun $(\mathrm{P}<0,01)$. Tutkimuksessamme häkkiryhmän lisärehuna käytettiin samalta laidunlohkolta niitettyä rehua, mutta lehmien laiduntamisajan on havaittu lyhenevän myös, kun lisärehuna on tarjottu säilörehua (Phillips \& Hecheimi 1989). Phillips ja Hecheimi (1989) havaitsivat myös, että lehmien lisärehuna tarjotun säilörehun syönti lisääntyi laitumen kasvuston lyhentyessä.

Kaikkiaan häkkiryhmän lehmät käyttivät syömiseen vähemmän aikaa kuin kontrolliryhmän eläimet (keskimäärin 6,1 vs. 7,1 h vuorokaudesta, $\mathrm{P}<0,001$ ). Häkkiryhmän pienempi kokonaissyömisaika voi johtua naudan kyvystä syödä nopeammin valmiiksi silputtua rehua kuin laidunta (Phillips 1993). Häkkiryhmän eläimet märehtivät kokeen aikana enemmän kuin kontrolliryhmän eläimet (keskimäärin 6,9 vs. 6,3 h vuorokaudesta, $\mathrm{P}<0,05)$. Kontrolli- ja häkkiryhmän lehmien välillä ei ollut eroa lehmien kävelemiseen (keskimäärin 0,2 vs. $0,2 \mathrm{~h}$ vuorokaudesta), muuhun aktiivisuuteen makuulla ja seisaalla (1,0 vs. $1,1 \mathrm{~h})$, joutilaana makaamiseen ja seisomiseen $(3,0$ vs. 3,3 h) tai yhteensä makaamiseen $(8,6$ vs. 9,1 h) käyttämässä ajassa. 
Taulukko 2. Ajankäytön jakautuminen tunteina vuorokaudesta eri toiminnoille heinä- ja elokuussa tavanomaisesti laiduntavilla ja häkistä lisärehua saavilla lehmillä.

\begin{tabular}{|c|c|c|c|c|c|c|c|c|c|}
\hline & \multicolumn{2}{|c|}{ Kontrolli } & \multicolumn{3}{|c|}{ Häkki } & & \multicolumn{3}{|c|}{ Tilastollinen merkitsevyys } \\
\hline & heinä & elo & SEM $^{1}$ & heinä & elo & SEM & käsittely & kuukausi & $\begin{array}{l}\text { käsittely x } \\
\text { kuukausi }\end{array}$ \\
\hline laiduntaa & 7,2 & 7,0 & 0,26 & 3,3 & 3,8 & 0,27 & $* * *$ & & o \\
\hline syö häkkirehua & 0,0 & 0,0 & - & 2,3 & 2,8 & 0,24 & $* * *$ & $*$ & $*$ \\
\hline syö yhteensä & 7,1 & 7,0 & 0,19 & 5,6 & 6,5 & 0,20 & $* * *$ & $*$ & $* *$ \\
\hline märehtii & 6,6 & 6,1 & 0,21 & 6,6 & 7,1 & 0,22 & $*$ & & $* *$ \\
\hline kävelee & 0,14 & 0,26 & 0,06 & 0,16 & 0,16 & 0,06 & & & \\
\hline $\begin{array}{l}\text { joutilaana olo } \\
\text { makuulla ja } \\
\text { seisaalla }\end{array}$ & 2,4 & 3,5 & 0,23 & 3,4 & 3,2 & 0,23 & o & $*$ & $* *$ \\
\hline $\begin{array}{l}\text { muu aktiivisuus } \\
\text { makuulla ja } \\
\text { seisaalla }\end{array}$ & 1,1 & 1,0 & 0,12 & 1,4 & 0,8 & 0,13 & & $* *$ & o \\
\hline lypsyllä & 6,7 & 6,2 & & 6,8 & 6,3 & & & & \\
\hline makaa yhteensä & 8,4 & 8,7 & 0,29 & 8,8 & 9,3 & 0,30 & & $*$ & \\
\hline
\end{tabular}

${ }^{1}$ Keskiarvon keskivirhe. Tilastollinen merkitsevyys: * $\mathrm{P}<0,05 ; * * \mathrm{P}<0,01 ; * * * \mathrm{P}<0,001 ;$ o $\mathrm{P}<0,1$

Syömisjaksot sijoittuivat kontrolli- ja häkkiryhmällä samoihin vuorokaudenaikoihin (Kuva 2). Eniten laiduntamista ja häkkirehun syöntiä esiintyi heti lypsyjen jälkeen. Häkkiryhmän eläimet eivät selkeästi mihinkään vuorokaudenaikaan pelkästään laiduntaneet tai syöneet häkkirehua, vaan molempia ravinnonhankintatapoja esiintyi rinnakkain ympäri vuorokauden. Lehmät eivät myöskään näyttäneet suosivan häkkirehua enemmän, kun laidun tallautui tai lyheni laiduntamisen myötä. Rehujätettä jäi molempien koejaksojen päättyessä ruokintahäkkiin (heinäkuussa 81,4 $\pm 29,1$ (keskiarvo \pm keskihajonta) kg ja elokuussa 162,2 $\pm 144,0 \mathrm{~kg}$ ). Rehu saattoi kuitenkin ajoittain olla vähissä ennen seuraavaa täydennystä, mikä on voinut ajaa häkkirehun syömisestäkin kiinnostuneet lehmät laiduntamaan.

Ruokintahäkissä oli teoreettisesti ruokailutilaa kaikille lehmille. Enimmillään havaitsimme kokeessamme kuuden lehmän olevan syömässä ruokintahäkillä samanaikaisesti, mikä on vain puolet häkkiryhmän lehmien lukumäärästä. Bouissoun ym. (2001) mukaan mitä suurempi ero lehmien sosiaalisessa arvossa on, sitä kauempana eläimet pyrkivät syömään toisistaan ruokintapöydällä. Tällöin alempiarvoiset eläimet, kuten ensikot, saattoivat olla vanhempia lehmiä huonommassa asemassa häkkirehun syömisen suhteen ja joutua laiduntamaan, vaikka niillä olisi ollut kiinnostusta syödä häkkirehua. Häkkiryhmän ensikot käyttivät häkistä syömiseen keskimäärin $2,0 \pm 0,8 \mathrm{~h}$ vuorokaudesta ja kaksi tai useamman kerran poikineet eläimet $2,9 \pm 0,9 \mathrm{~h}$. Yhteensä häkkiryhmän ensikot käyttivät laiduntamiseen ja häkkirehun syömiseen keskimäärin $6,1 \pm 0,3 \mathrm{~h}$ vuorokaudesta ja kaksi tai useamman kerran poikineet eläimet $6,1 \pm 0,6 \mathrm{~h}$. Myös terveydentila saattoi vaikuttaa lehmien tekemiin valintoihin. Jos lehmällä on jalkaongelmia, sen saattaa olla mieluisampaa hankkia ravintonsa häkistä paikallaan seisten, kuin laiduntamalla. Silmämääräisten havaintojen perusteella vanhemmilla lehmillä oli kokeessamme enemmän jalkaongelmia kuin nuorilla. 

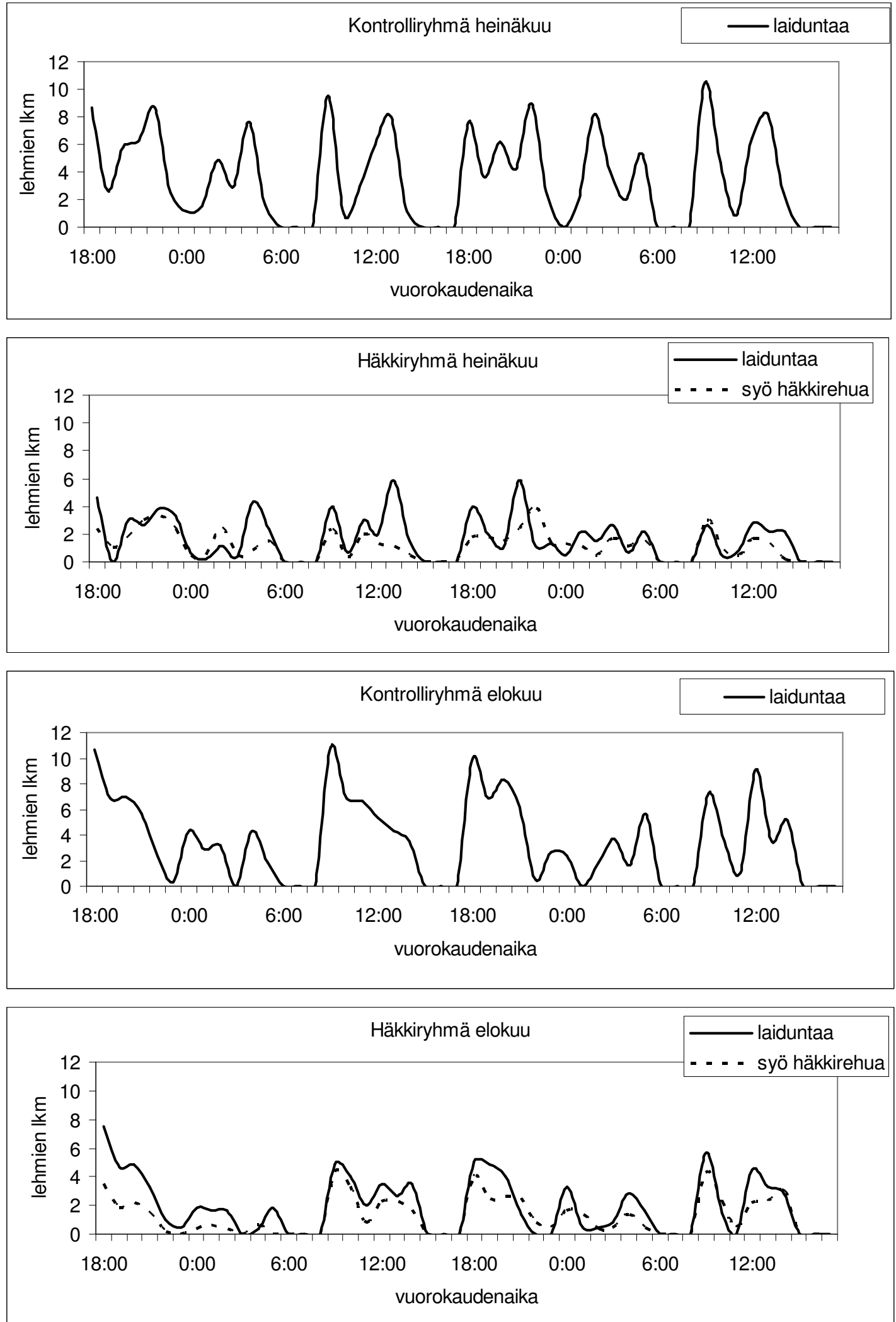

Kuva 1. Kontrolli- ja häkkiryhmän lehmien laiduntamisen ja häkkirehun syömisen vuorokausirytmit heinä- ja elokuussa. Lehmät olivat lypsyllä aamulla klo 05:30-09:00 ja illalla klo 14:30-18:00. 


\section{Johtopäätökset}

Kun lehmille annettiin mahdollisuus hankkia ravintonsa laiduntamalla tai syömällä ruokintahäkistä, ne valitsivat helpomman häkkiruokintavaihtoehdon vain osittain. Kokeemme tulokset viittaavat siihen, että lehmällä on tarve hankkia ainakin osa ravinnostaan laiduntamalla. Lehmän sosiaalinen asema ja terveys saattavat kuitenkin vaikuttaa yksittäisen lehmän tekemään valintaan, minkä vuoksi aiheesta kaivattaisiin lisätutkimuksia.

\section{Kirjallisuus}

Bouissou, M.F., Boissy, A., le Neindre, P. \& Veissier, I. 2001. The Social Behaviour of Cattle. Teoksessa: Keeling, L.K. \& Gonyou, H.W. (toim.). Social behavior in farm animals. 1. painos. Cambridge: CABI Publishing, s. 113-145.

Gustafson, G.M. 1993. Effects of daily exercise on the health of tied dairy cows. Prev. Vet. Med. 17: 209-223.

Haskell, M.J., Rennie, L.J., Bowell, V.A., Bell, M.J. \& Lawrence, A.B. 2006. Housing system, milk production, and zero-grazing effects on lameness and leg injury in dairy cows. J. Dairy Sci. 89: 4259-4266.

Holma, U. 2008. Ulkoilun hyödyt ja haasteet. Teoriaa ja käytäntöjä nautojen ulkoilusta. Mikkeli: Helsingin yliopisto, Ruralia-instituutti. $39 \mathrm{~s}$.

Martin, P. \& Bateson, P. 1993. Measuring behaviour. An introductory guide. Toinen painos. United Kingdom: Cambridge University Press. 222 s.

Phillips, C.J.C. 1993. Cattle behaviour. United Kingdom: Farming press. $212 \mathrm{~s}$.

Phillips, C.J.C. \& Hecheimi, K. 1989: The effect of forage supplementation, herbage height and season on the ingestive behaviour of dairy cows. Appl. Anim. Behav. Sci. 24: 203-216.

Sairanen, A., Hakosalo, J., Virkajärvi, P., Mononen, J., Kauppinen, R., Khalili, H., Ahola, L. \& Lindeberg, H. 2004. Osittaislaidunnuksen vaikutus lehmien tuotokseen ja hyvinvointiin. Teoksessa: Hopponen, A. \& Rinne, M. (toim.). Maataloustieteen päivät 2004, 12.-13.1.2004 Viikki, Helsinki. Suomen maataloustieteellisen seuran tiedote $19.4 \mathrm{~s}$.

Valtioneuvoston asetus 171/2005. Valtioneuvoston asetus eläinsuojeluasetuksen muuttamisesta. Annettu Helsingissä 17.3.2005. Viitattu 23.11.2009. Saatavissa internetistä: http://wwwb.mmm.fi/el/laki/f/f2m5.pdf. 